\title{
Comparison of the efficacy of self-expandable metallic stents in colorectal obstructions caused by extracolonic malignancy and colorectal cancer
}

\author{
TOMOE SANO, YUJIRO NOZAWA, AKITO IWANAGA, MOTOI AZUMI, \\ MICHITAKA IMAI, TORU ISHIKAWA, TERASU HONMA and TOSHIAKI YOSHIDA
}

Department of Gastroenterology and Hepatology, Saiseikai Niigata Hospital, Niigata 950-1104, Japan

Received February 12, 2021; Accepted June 1, 2021

DOI: $10.3892 / \mathrm{mco} .2021 .2332$

\begin{abstract}
The current study aimed to compare the safety and effectiveness of self-expandable metallic stent placement among patients with extracolonic malignancy and those with colorectal cancer. Patient information, technical and clinical success rates and complication rates were compared between patients with colorectal cancer and extracolonic malignancy. The Kaplan-Meier method was used to compare the time elapsed before the onset of complications. Risk factors for re-obstruction in patients with self-expandable metallic stents were evaluated by multivariate analysis. A total of 68 patients who underwent self-expandable metallic stent placement at Saiseikai Niigata Hospital between January 2012 and September 2019 were included. The clinical success rate was significantly different between the colorectal cancer $(96.6 \%)$ and extracolonic malignancy $(66.7 \%)$ groups $(\mathrm{P}=0.01)$. The incidence of complications was significantly higher in the extracolonic malignancy group $(66.7 \%)$ than in the colorectal cancer group (25.4\%; $\mathrm{P}=0.02)$. Additionally, the time elapsed before the onset of complications was shorter in the extracolonic malignancy group than in the colorectal cancer group ( $\mathrm{P}=0.0008)$. Risk factors for re-obstruction were higher in the extracolonic malignancy group [odds ratio, $7.76(1.02-57.2)]$ than in the palliative stent placement group [odds ratio, 5.45 (1.01-29.5); $\mathrm{P}=0.04]$. In extracolonic malignancy, self-expandable metallic stent placement was associated with lower clinical success rates and increased risk of complications. The time elapsed before the onset of complications was short, and extracolonic malignancy was a risk factor for re-obstruction, suggesting that the placement
\end{abstract}

Correspondence to: Dr Tomoe Sano, Department of Gastroenterology and Hepatology, Saiseikai Niigata Hospital, Teraji 280-7, Niigata 950-1104, Japan

E-mail: sano.t@ngt.saiseikai.or.jp

Key words: self-expandable metallic stent, malignant colorectal obstruction, extracolonic malignancy, re-obstruction, clinical success rate, technical success rate of self-expandable metallic stents for malignant colorectal obstruction in extracolonic malignancy is not optimal.

\section{Introduction}

Acute malignant colorectal obstruction is a complication of colorectal cancer (CRC) occurring in 7-29\% of patients (1-4) and is associated with rapid colonic decompression, requiring interventions, such as colostomy, resection, and ileal tube placement. However, these emergency procedures are associated with high rates of mortality and morbidity (5-9). In 1990, Dohmoto et al first reported on colon stent placement [self-expandable metallic stents (SEMSs)] for palliation of malignant colorectal obstruction (10). Indications for the placement of SEMS also include pre-operative colonic decompression (11). Recently, SEMS has become widely available and is now considered an alternative therapeutic option for the management of colorectal obstruction secondary to CRC $(5,12,13)$. However, malignant colorectal obstruction is caused by CRC and by infiltration and dissemination of extracolonic malignancy (ECM), such as gastric, pancreatic, gynaecologic, and urinary system cancers $(5,14-19)$. Obstruction in CRC results from intraluminal growth; ECM leads to the development of intestinal obstruction owing to external invasion or compression, and the axis of the colon may change $(14,20)$. Some studies have reported the safety and efficacy of SEMS placement for malignant colorectal obstruction in patients with CRC; however, only a few studies have reported the use of SEMS placement for diseases caused by $\operatorname{ECM}(5,11,14-23)$. Ahn et al (23) performed SEMS placement in 72 patients with colorectal obstruction by ECM, with $90.3 \%$ technical success rate and $87.7 \%$ clinical success rate. However, Ahn et al did not report any comparison with the CRC group; thus, it is unclear whether SEMS is equally effective for CRC as well as ECM patients. Therefore, the safety and efficacy of SEMS placement for ECM currently remain unknown. In this study, we aimed to compare the clinical and technical success between CRC and ECM when an SEMS is placed for malignant colorectal obstruction. In addition, the incidence of perforation, re-obstruction, and migration as complications was examined and compared between the ECM and CRC groups. The time elapsed before 
the onset of complications was also compared between the two groups using the Kaplan-Meier method. In addition, risk factors for re-obstruction were extracted through a multivariate analysis.

\section{Materials and methods}

Study subjects. We retrospectively evaluated the endoscopy and clinical records of 68 patients who underwent procedures for SEMS placement at our institution due to malignant colorectal obstruction between January 2012 and September 2019. All patients provided a written approval agreement. Patients who had SEMS placement for benign diseases, such as diverticulosis and postoperative stenosis, were excluded from this study. The study was approved by the Standards of Official Conduct Committee at Saiseikai Niigata Hospital (IRB no. E17-28). This study adhered to the principles of the Declaration of Helsinki of 1964.

SEMS placement was performed under endoscopic/fluoroscopic guidance (24). Patients used analgesics (pentazocine; 7.7-15 mg) and sedatives (midazolam; 5-10 mg) in response to their distress during the SEMS placement procedure. A wide working channel endoscope (CF-H260AI, CF-H290I, CF-HQ290I, PCF-Q260JI; Olympus) was introduced into the stenosed portion. The site of stenosis was detected on endoscopic imaging or was visualized using a contrast medium under fluoroscopic and endoscopic guidance (Fig. 1A). A biliary guidewire ( 0.035 inches) was passed to traverse the obstruction until a safety loop of the guidewire could be created. A biliary catheter was then advanced to follow it. A water-soluble contrast agent (amidotrizoic acid) was injected into the proximal side of the stricture in order to assess it; we evaluated the stricture and measured its exact length. The suitable length of the stent was determined by adding $2-5 \mathrm{~cm}$ to the length of the stricture. A longer stent was used for the stricture of the flexion or $\operatorname{ECM}(20,25)$. The delivery system was inserted through the guidewire facilitating entry into the site of obstruction (Fig. 1B). While the outer sheath was retracted under fluoroscopy with endoscopic guidance, the centre of the stent was adjusted at the narrowest point (21) (Fig. 1C and D).

Statistical analysis. Statistical analysis was conducted using the EZR software (Saitama Medical Center, Jichi Medical University, Saitama, Japan) (26). Patients' information and clinical characteristics were presented as means \pm standard deviations, and median and range. The means of continuous variables were compared between the CRC and ECM groups using the Student's t-test or the Mann-Whitney U test, as appropriate. Differences in outcomes between the two groups were examined using $\chi^{2}$ or Fisher's exact tests. In addition, the time elapsed before the onset of complications after stent placement was analysed using the Kaplan-Meier method in both groups, and their curves were compared using the log-rank method. In addition, multivariate analysis (logistic regression) was performed on risk factors for re-obstruction.

The results are expressed as mean \pm standard deviation or as percentages. P-values of $<0.05$ were considered statistically significant.
Definitions. Technical success was defined as successful deployment of the stent across the entire length of the stricture, without any adverse events e.g., perforation, stent migration, and major bleeding. Clinical success was defined as colonic decompression and relief of obstructive symptoms within $48 \mathrm{~h}$ of stent placement, with no need for reintervention $(14,27)$.

The Colorectal Obstruction Scoring System (CROSS) is a scoring system proposed by the Colonic Stent Safe Procedure Research Group of Japan. To make scoring intestinal obstruction as simple as possible, the CROSS asks about the patient's oral intake and whether the patient is symptomatic, despite being able to eat. It is described as follows: Score 0: Requiring a continuous decompressive procedure; score 1: No oral intake; score 2: Liquid or enteral nutrients; score 3: Soft solids, low-residue, and full diet with symptoms of stricture; and score 4: Soft solids, low-residue, and full diet without symptoms of stricture (28). CROSS scores before and after stent placement in both groups were compared and analysed using nonparametric tests.

\section{Results}

SEMS placement was performed for CRC in 59/68 patients $(86.8 \%)$ at our institution. Of the 9/68 ECM patients (13.2\%), indications for SEMS placement were pancreatic $(n=4)$, gastric $(n=4)$, and oesophageal $(n=1)$ cancers. Patients' demographics and stent details are summarised in Table I. No significant differences were noted in age, male-to-female ratio, site of obstruction, and clinical stage between the CRC and ECM groups. The length and width of stents were chosen depending on the length and degree of flexion of the stenotic portion of the colon. Uncovered stents were used in all patients, and there were no significant differences in the length, width, or type of stent between the two groups. In the CRC group, 30 patients $(50.8 \%)$ underwent surgery (28 patients underwent colectomy and two underwent colostomy) after stent placement, and 29 patients (49.2\%) underwent palliative placement. All patients in the ECM group had a palliative placement, and there was a significant difference between the two groups with respect to the purpose of stent placement $(\mathrm{P}=0.003)$. There was no significant difference in the combination of chemotherapy in the overall course between the two groups: 27 patients $(45.8 \%)$ in the CRC group and seven patients (77.8\%) in the ECM group. However, six patients $(10.2 \%)$ in the CRC group (XELOX + Bevacizumab, XELOX, mFOLFOX6 + Cetuximab) and 5 patients (55.6\%) in the ECM group (GEM, CDDP + 5-FU, TS-1 + CDDP) received chemotherapy prior to stenting, showing a significant difference $(\mathrm{P}=0.004$; Table I).

Clinical outcomes. The technical success rate of stent placement was $98.3 \%$ in the CRC group and $100 \%$ in the ECM group, with no significant difference. In the CRC group, there was one case of perforation of the guidewire at the time of placement, which resulted in emergency surgery. The clinical success rate was significantly different between the CRC (96.6\%) and ECM (66.7\%) groups $(\mathrm{P}=0.01)$. The CROSS score before stent placement did not significant differ between the CRC (0.508 \pm 1.006$)$ and ECM $(0.222 \pm 0.441)$ groups. However, 
Table I. Baseline characteristics of patients in the CRC and ECM groups.

\begin{tabular}{|c|c|c|c|c|c|}
\hline $\begin{array}{l}\text { Characteristic } \\
\text { Cases }\end{array}$ & $\begin{array}{c}\mathrm{CRC}(\mathrm{n}) \\
59\end{array}$ & $\%$ & $\begin{array}{c}\mathrm{ECM}(\mathrm{n}) \\
9\end{array}$ & $\%$ & P-value \\
\hline Age & $73.17 \pm 13.15$ & $(46-95)$ & $69.11 \pm 9.83$ & $(55-88)$ & 0.379 \\
\hline Male/female & $32 / 27$ & & $5 / 4$ & & NS \\
\hline \multicolumn{6}{|l|}{ Site of obstruction } \\
\hline Right side colon & 19 & 32.2 & 4 & 44.4 & 0.710 \\
\hline Left side colon & 40 & 67.8 & 5 & 55.5 & \\
\hline \multicolumn{6}{|l|}{ cStage } \\
\hline II & 16 & 27.1 & 0 & 0.0 & 0.217 \\
\hline IIIa & 11 & 18.6 & 0 & 0.0 & \\
\hline IIIb & 2 & 3.4 & 0 & 0.0 & \\
\hline IV & 30 & 50.8 & 9 & 100.0 & \\
\hline \multicolumn{6}{|l|}{ Primary site } \\
\hline Pancreas & & & 4 & 0.4 & \\
\hline Stomach & & & 4 & 0.4 & \\
\hline Esophagus & & & 1 & 0.1 & \\
\hline \multicolumn{6}{|l|}{ Stent } \\
\hline Uncovered & 59 & 100.0 & 9 & 100.0 & NS \\
\hline Length (cm) & $9.47 \pm 2.42$ & $(6-12)$ & $10.67 \pm 1.32$ & $(9-12)$ & 0.154 \\
\hline Width (mm) & $20.44 \pm 1.97$ & $(18-22)$ & $20.22 \pm 2.11$ & $(18-22)$ & 0.759 \\
\hline \multicolumn{6}{|l|}{$\begin{array}{l}\text { Product name } \\
\text { of the stent }\end{array}$} \\
\hline Niti-S & 42 & 71.2 & 5 & 55.6 & 0.415 \\
\hline Wall Flex & 6 & 10.2 & 2 & 22.2 & \\
\hline JENTLLY & 8 & 13.6 & 1 & 11.1 & \\
\hline HANARO & 3 & 5.1 & 1 & 11.1 & \\
\hline \multicolumn{6}{|l|}{ Purpose } \\
\hline BTS & 30 & 50.8 & 0 & 0.0 & 0.004 \\
\hline PAL & 29 & 49.2 & 9 & 100.0 & \\
\hline \multicolumn{6}{|l|}{ Chemotherapy } \\
\hline All & 27 & 45.8 & 7 & 77.8 & 0.150 \\
\hline Prior stenting & 6 & 10.2 & 5 & 55.6 & 0.004 \\
\hline
\end{tabular}

CRC, colorectal cancer; ECM, extracolonic malignancy; BTS, bridge to surgery; PAL, palliation stent placement; NS, not significant.

there was a significant difference in the CROSS score after stenting between the CRC $(3.881 \pm 0.59)$ and ECM $(2.778 \pm 1.856)$ groups $(\mathrm{P}=0.0006)$, indicating a poorer improvement in the colorectal obstruction score in the ECM group. Complications were observed in 15 patients $(25.4 \%)$ in the CRC group and in six patients $(66.7 \%)$ in the ECM group, showing significant difference $(\mathrm{P}=0.02)$. Complications were further investigated according to types, such as perforation, migration, and re-obstruction. There was no significant difference in the number of perforations between the $\mathrm{CRC}$ (four patients, 6.8\%) and ECM (two patients, 22.2\%) groups. Two patients in the ECM group who underwent stent-in-stent placement with stent re-obstruction developed perforation. One patient underwent emergency surgery, and one patient was treated conservatively. In the CRC group, three of the four patients with perforation underwent emergency surgery, and one patient was treated conservatively. One patient received chemotherapy with ramucirumab post-stent placement, another had pancreatic cancer with extensive peritoneal dissemination, and the other had re-obstruction of the stent and received a stent-in-stent placement. There were four $(6.8 \%)$ cases of migration in the CRC group and none in the ECM group. The migration occurred in patients whose tumours had shrunk with chemotherapy. Re-obstruction occurred in 10 patients in the CRC group $(16.9 \%)$ and six patients in the ECM group (66.7\%), showing statistically significant difference $(\mathrm{P}=0.004)$. At the time of experiencing complications, there were 4/6 (66.7\%) patients in the ECM group and 4/15 (26.7\%) in the CRC group who required emergency surgery (colostomy or ileostomy), although the difference was not significant. There was no significant difference in the number of patients who underwent endoscopic procedures (addition of stents, stent cleaning, or dilation) between the ECM and CRC groups [1/6 (16.7\%) vs. 5/15 (33.3\%)] (Table II). 
Table II. Clinical outcomes of patients in the CRC and ECM groups.

\begin{tabular}{|c|c|c|c|c|c|}
\hline Outcome & CRC $(n=59)$ & $\%$ & ECM $(n=9)$ & $\%$ & P-value \\
\hline Technical success & 58 & 98.3 & 9 & 100.0 & NS \\
\hline Clinical success & 57 & 96.6 & 6 & 66.7 & 0.015 \\
\hline \multicolumn{6}{|l|}{ CROSS } \\
\hline Before stent placement & $0.508 \pm 1.006$ & & $0.222 \pm 0.441$ & & 0.406 \\
\hline After stent placement & $3.881 \pm 0.590$ & & $2.778 \pm 1.856$ & & $<0.001$ \\
\hline \multicolumn{6}{|l|}{ Complication } \\
\hline All & 15 & 25.4 & 6 & 66.7 & 0.021 \\
\hline Perforation & 4 & 6.8 & 2 & 22.2 & 0.177 \\
\hline Migration & 4 & 6.8 & 0 & 0.0 & NS \\
\hline Reobstruction & 10 & 16.9 & 6 & 66.7 & 0.004 \\
\hline Emergency surgery ${ }^{\mathrm{a}}$ & 4 & $\begin{array}{c}26.7 \\
(4 / 15)\end{array}$ & 4 & $\begin{array}{l}66.7 \\
0.146\end{array}$ & 0.146 \\
\hline Endoscopic procedure $^{\mathrm{b}}$ & 5 & $\begin{array}{c}33.3 \\
(5 / 15)\end{array}$ & 1 & $\begin{array}{l}16.7 \\
(1 / 6)\end{array}$ & 0.623 \\
\hline
\end{tabular}

${ }^{\text {aS }}$ urgery includes colostomy or ileostomy. ${ }^{\mathrm{b} I n c l u d e s}$ stent reintervention. CRC, colorectal cancer; ECM, extracolonic malignancy; CROSS, The Colorectal Obstruction Scoring System; NS, not significant.

Table III. Multivariate analysis of risk factors for re-obstruction.

\begin{tabular}{llr}
\hline Risk factor & Odds ratio (95\% CI) & P-value \\
\hline ECM & $7.76(1.02-57.20)$ & 0.044 \\
Prior chemotherapy & $1.02(0.20-5.27)$ & 0.984 \\
PAL & $5.45(1.01-29.50)$ & 0.049 \\
CROSS after stent placement & $1.38(0.69-2.78)$ & 0.367 \\
\hline
\end{tabular}

ECM, extracolonic malignancy; PAL, palliative stent placement; CROSS, The Colorectal Obstruction Scoring System; CI, confidence interval.
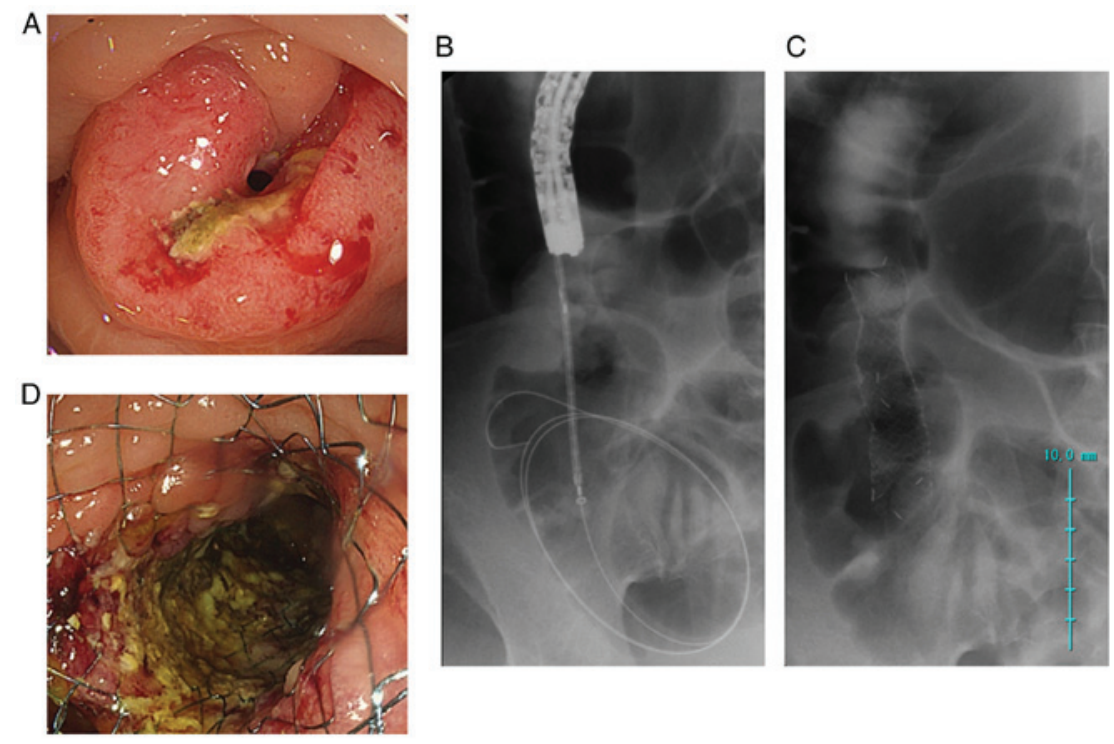

Figure 1. Self-expandable metallic stent placement. (A) Malignant colorectal obstruction due to cancer of the ascending colon. The stenosis appears as a pinhole in endoscopic views. The endoscope failed to pass through the stenosis. (B) A guidewire and catheter were used to penetrate the stenosis and a guidewire of sufficient length was deployed to draw a loop proximal to the stenosis. The delivery system was inserted through the guidewire and was guided fluoroscopically into the obstruction site. While the outer sheath was retracted under fluoroscopy with endoscopic guidance, the centre of the stent was adjusted at the narrowest point. (C) The safety lock of the delivery system was unlocked. The inner shaft was immobilised and the outer sheath was gently pulled to deploy the stent. Once the stent was fully deployed, the delivery system was withdrawn. (D) When the stent was deployed, faecal discharge and gas were confirmed. The Niti-S Enteral Colonic Uncontrolled Stent (100x18 mm; Taewoong Medical) was used as the stent. 


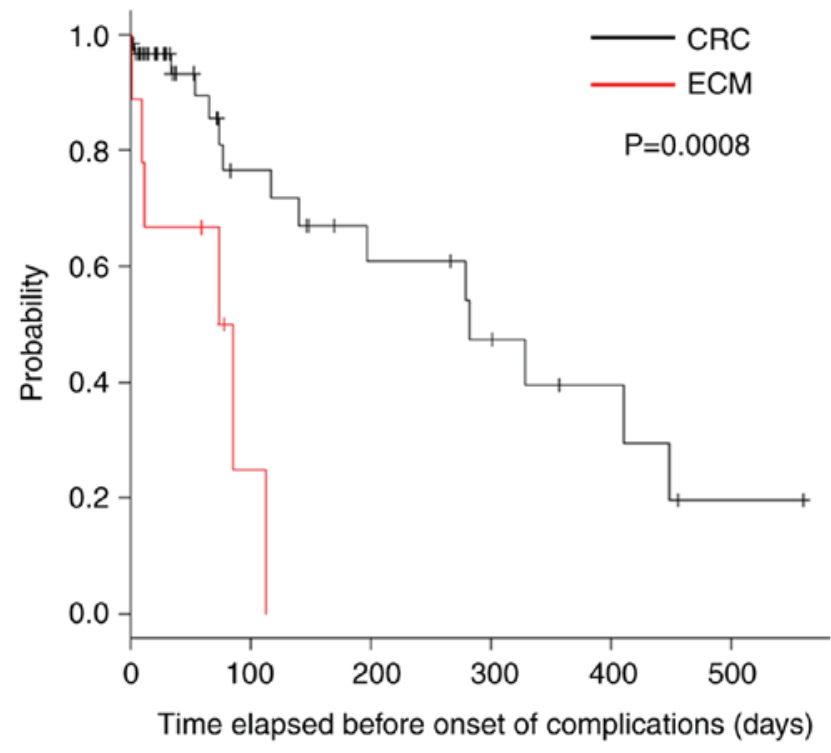

Figure 2. Time elapsed before the onset of complications was compared between the CRC and ECM groups using the Kaplan-Meier method. The duration until complications was significantly shorter in the ECM group $(\mathrm{P}=0.0008$; calculated using the log-rank method). $\mathrm{CRC}$, colorectal cancer; ECM, extracolonic malignancy.

When the time elapsed before the onset of complications was compared between the two groups, the time was shorter in the ECM group ( $\mathrm{P}=0.0008$; Fig. 2). In addition, a multivariate analysis of risk factors for re-obstruction after SEMS placement was performed. Logistic regression analysis was performed using ECM, palliative purpose, CROSS score post-stenting, and prior chemotherapy as the independent variables. Risk factors for re-obstruction were higher for ECM [odds ratio (OR): 7.76 (1.02-57.2), $\mathrm{P}=0.04$ ] than for palliative stent placement (OR: 5.45 (1.01-29.5), $\mathrm{P}=0.05$; Table III).

\section{Discussion}

A systematic review reported a technical success rate of $96.2 \%$ (range 66.6-100\%) and a clinical success rate of 92\% (range 46-100\%) in patients with CRC (20,29-31). In contrast, among patients with ECM, the technical success rate was $88.5 \%$ (range 67-100\%) and the clinical success rate was $72.2 \%$ (range $20-100 \%)$ in the 12 reviewed articles $(14,15,19-21,25,32-35)$. In our study, there was no difference in the technical success rate between the CRC and ECM groups, but the clinical success rate was significantly lower in the ECM group, which was similar to previous reports. In addition, the incidence of complications was significantly higher in the ECM group, and the incidence of occlusion was particularly high. Although SEMS is preferred over emergency surgery for colorectal obstruction, the efficacy of SEMS in patients with malignant colorectal obstruction by ECM with peritoneal carcinomatosis has not been demonstrated to date (22). Compared to obstructions associated with CRC, those caused by ECM tend to be complicated at one or more potential locations (21). Kim et al reported no significant difference in clinical success, complication, and stent patency rates between the CRC and ECM groups (22). Ahn et al reported that 72 patients with colorectal obstruction caused by ECM were treated with uncovered SEMS.
The technical success rate was $90.3 \%$ with a clinical success rate of $87.7 \%$. However, despite the high clinical success rate, $26.3 \%(15 / 57)$ of the patients ultimately required surgery in the long term (23). The rate of surgery in their ECM group was lower than that in our ECM group [44.4\% (4/9)], but it was higher than that in our CRC group [7.02\% (4/57)]. In addition, since Ahn et al did not compare their data with the CRC group; it is unclear whether SEMS is equally effective for CRC as well as ECM patients. However, we agree with the opinion of Ahn et al that SEMS placement with colorectal obstruction caused by ECM is effective in selected patients considering their prognosis because SEMS is less burdensome compared to surgery (23). Keswani et al demonstrated that patients with ECM had a significantly lower clinical success rate than those with CRC (94.1 vs. 20\%; P<0.0001), but they have a higher rate of complications $(\mathrm{P}=0.046)$. Moreover, the multivariable analysis revealed that ECM was a predictor of complications (20). In our study, one patient in the CRC group developed perforation during SEMS placement at the ascending colon when using a guidewire to traverse the obstruction. However, both groups showed high technical success rates. With regard to the clinical success, all patients in the CRC group showed clinical improvement, but some patients in the ECM group did not show clinical improvement even after successful stent placement. In our study, re-obstruction occurred in the CRC group at 6 months after stent placement, with a longer placement resulting in in-growth and stool impaction. In the ECM group, re-obstruction occurred relatively earlier after stent placement (median patency duration: 79 days).

One patient in the CRC group developed perforation when receiving ramucirumab treatment. Ramucirumab and bevacizumab are anti-VEGF antibody drugs that have been reported to be associated with the risk of gastrointestinal perforation during stent placement (36).

Faraz et al reported that the technical and clinical success rates are decreased in patients with peritoneal carcinomatosis and multifocal disease. However, these factors should not discourage attempts for stent placement, especially if the benefits outweigh the risks (37). Furthermore, the use of SEMS should be carefully considered for patients who respond to chemotherapy, which results in longer survival duration, as the ECM group is likely to have a shorter stent patency duration. In some cases, colorectal obstruction associated with ECM did not improve after SEMS placement. These patients presented with multiple stenoses, intestinal stenosis, impaired bowel movement, or impaired digestive tract motility owing to the presence of an omental cake $(14,20,21)$. Colorectal stents may be an excellent palliative treatment option compared with surgery or an ileus tube. However, when complications occur, emergency surgery is often required in the ECM group. Therefore, careful consideration of the patient's presentation and prognosis is required when placing a stent in a patient with ECM. In addition, it is important that an adequate explanation is provided to patients and families regarding potential complications that may develop shortly after stent placement. In this study, as in previous reports, colorectal stent placement was inferior in the ECM group as compared to that in the CRC group in terms of safety and efficacy. Furthermore, patients in the ECM group had a significantly higher frequency of palliative stent placement 
and chemotherapy before stent placement than those in the CRC group. These factors were considered to be associated with a higher number of complications. However, the results of the multivariate analysis showed that the ECM group was a risk factor for re-obstruction. Keswani et al reported a similar conclusion (20). This retrospective, single-centre study, with its small number of patients, requires further expansion.

In conclusion, in patients with ECM, SEMS placement was associated with a lower clinical success rate and increased risk for complications, especially re-obstruction. The time elapsed before the onset of complications was short, and the ECM itself was a risk factor for re-obstruction, suggesting that placement of SEMS for malignant colorectal obstruction in ECM is not optimal.

\section{Acknowledgements}

Not applicable.

\section{Funding}

No funding was received.

\section{Availability of data and materials}

All data generated or analysed during this study are included in this published article.

\section{Authors' contributions}

TS designed the current study and established patient selection criteria. TS, YN, AI, MA, MI, TI, TH and TY formed the study groups, analysed and interpreted patient data, and wrote the manuscript. TS and AI confirm the authenticity of all the raw data. All authors read and approved the final manuscript and agree to be accountable for all aspects of the research in ensuring that the accuracy or integrity of any part of the work are appropriately investigated and resolved.

\section{Ethics approval and consent to participate}

The current study was approved by the Standards of the Official Conduct Committee at Saiseikai Niigata Hospital (approval no. E17-28). All patients provided written informed consent and the current study adhered to the principles of the Declaration of Helsinki of 1964.

\section{Patient consent for publication}

Not applicable.

\section{Competing interests}

The authors declare that they have no competing interests.

\section{References}

1. Frago R, Ramirez E, Millan M, Kriesler E, del Valle E and Biondo S: Current management of acute malignant large bowel obstruction: A systematic review. Am J Surg 207: 127-138, 2014.
2. Pisano M, Zorcolo L, Merli C, Cimbanassi S, Poiasina E, Ceresoli M, Agresta F, Allievi N, Bellanova G, Coccolini F, et al: 2017 WSES guidelines on colon and rectal cancer emergencies: Obstruction and perforation. World J Emerg Surg 13: 36, 2018.

3. Cheynel N, Cortet M, Lepage C, Benoit L, Faivre J and Bouvier AM: Trends in frequency and management of obstructing colorectal cancers in a well-defined population. Dis Colon Rectum 50: 1568-1575, 2007.

4. Deans GT, Krukowski ZH and Irwin ST: Malignant obstruction of the left colon. Br J Surg 81: 1270-1276, 1994.

5. Faraz S, Salem SB, Schattner M, Mendelsohn R, Markowitz A Ludwig E, Zheng J, Gerdes H and Shah PM: Predictors of clinical outcome of colonic stent in patents with malignant large-bowel obstruction because of extracolonic malignancy. Gastrointest Endosc 87: 1310-1317, 2018.

6. Sebastian S, Johnston S, Geoghegan T, Torreggiani W and Buckley M: Pooled analysis of the efficacy and safety of self-expanding metal stenting in malignant colorectal obstruction. Am J Gastroenterol 99: 2051-2057, 2004.

7. Carne PW, Frye JN, Robertson GM and Frizelle FA: Stents or open operation for palliation of colorectal cancer: A retrospective, cohort study of perioperative outcome and long-term survival. Dis Colon Rectum 47: 1455-1461, 2004.

8. Faragher IG, Chaitowitz IM and Stupart DA: Long-term results of palliative stenting or surgery for incurable obstructing colon cancer. Colorectal Dis 10: 668-672, 2008.

9. Angenete E, Asplund D, Bergström M and Park PO: Stenting for colorectal cancer obstruction compared to surgery-a study of consecutive patients in a single institution. Int J Colorectal Dis 27: 665-670, 2012.

10. DohmotoM,Rupp KD and Hohlbach G: Endoscopically-implanted prosthesis in rectal carcinoma. Dtsch Med Wochenschr 115: 915 , 1990 (In German).

11. van Hooft JE, van Halsema EE, Vanbiervliet G, Beets-Tan RG, DeWitt JM, Donellan F, Dumonceau JM, Glynne-Jones RG, Hassan C, Jiménez-Perez J, et al: Self-expandable metal stents for obstructing colonic and extracolonic cancer: European society of gastrointestinal endoscopy (ESGE) clinical guideline. Endoscopy 46: 990-1053, 2014.

12. Davila RE, Rajan E, Adler D, Hirota WK, Jacobson BC, Leighton JA, Qureshi W, Zuckerman MJ, Fanelli R, Hambrick D, et al: ASGE guideline: The role of endoscopy in the diagnosis, staging, and management of colorectal cancer. Gastrointest Endosc 61: 1-7, 2005.

13. Wang Y, Hu H, Wang M, Han X, Zhang Q, Yu L, Chen Y and Wang G: Self-expanding metallic stent as a bridge to surgery versus emergency surgery for acute obstructive colorectal cancer: A retrospective study. Cancer Manag Res 11: 2709-2718, 2019.

14. Kim BK, Hong SP, Heo HM, Kim JY, Hur H, Lee KY, Cheon JH, Kim TI and Kim WH: Endoscopic stenting is not as effective for palliation of colorectal obstruction in patients with advanced gastric cancer as emergency surgery. Gastrointest Endosc 75: 294-301, 2012.

15. Kim JY, Kim SG, Im JP, Kim JS and Jung HC: Comparison of treatment outcomes of endoscopic stenting for colonic and extracolonic malignant obstruction. Surg Endosc 27: 272-277, 2013.

16. Moon SJ, Kim SW, Lee BI, Lim CH, Kim JS, Soo J, Park JM, Lee IS, Choi MG and Choi KY: Palliative stent for malignant colonic obstruction by extracolonic malignancy: A comparison with colorectal cancer. Dig Dis Sci 59: 1891-1897, 2014.

17. Kim JH, Song HY, Park JH, Ye BD, Yoon YS and Kim JC: Metallic stent placement in the palliative treatment of malignant colonic obstructions: Primary colonic versus extracolonic malignancies. J Vasc Interv Radiol 22: 1727-1732, 2011.

18. Trompetas V, Saunders M, Gossage J and Anderson H: Shortcomings in colonic stenting to palliate large bowel obstruction from extracolonic malignancies. Int J Colorectal Dis 25: 851-854, 2010.

19. Shin SJ, Kim TI, Kim BC, Lee YV, Song SY and Kim WH: Clinical application of self-expandable metallic stent for treatment of colorectal obstruction caused by extrinsic invasive tumors. Dis Colon Rectum 51: 578-583, 2008.

20. Keswani RN, Azar RR, Edmundowicz SA, Zhang Q, Ammar T, Banerjee B, Early DS and Jonnalagadda SS: Stenting for malignant colonic obstruction: A comparison of efficacy and complications in colonic versus extracolonic malignancy. Gastrointest Endosc 69: 675-680, 2009.

21. Yoshida S, Isayama H and Koike K: Palliative self-expandable metallic stent placement for colorectal obstruction caused by an extracolonic malignancy. Gastrointest Interv 3: 75-79, 2014 
22. Kim JH, Ku YS, Jeon TJ, Park JY, Chung J-W, Kwon KA Park DK and Kim YJ: The efficacy of self-expanding metal stents for malignant colorectal obstruction by noncolonic malignancy with peritoneal carcinomatosis. Dis Colon Rectum 56: 1228-1232, 2013.

23. Ahn JS, Hong SN, Chang DK, Kim YH and Kim ER: Efficacy of uncovered self-expandable metallic stent for colorectal obstruction by extracolonic malignancy. World J Gastrointest Oncol 12: 1005-1013, 2020.

24. Keymling M: Colorectal stenting. Endoscopy 35: 234-238, 2003.

25. Keränen I, Lepistö A, Udd M, Halttunen J and Kylänpää L: Stenting for malignant colorectal obstruction: A single-center experience with 101 patients. Surg Endosc 26: 423-430, 2012.

26. Kanda Y: Investigation of the freely available easy-to-use software 'EZR' for medical statistics. Bone Marrow Transplant 48: 452-458, 2013

27. Matsuzawa T, Ishida H, Yoshida S, Isayama S, Kuwai T, Maetani I, ShimadaM,YamadaT,SaitoS,TomitaM,etal:AJapaneseprospective multicenter study of self-expandable metal stent placement for malignant colorectal obstruction: Short-term safety and efficacy within 7 days of stent procedure in 513 cases. Gastrointest Endosc 82: 697-707.e1, 2015.

28. Otsuji A, Saida Y, Enomoto T, Takabayashi K, Nakamura Y Katagi M, Nagao S, Watanabe R, Dotai K, Nagaoki Y, et al Feasibility of colorectal obstruction scoring system (CROSS) in colonic stent cases. Prog Dig Endosc 82: 68-71, 2013.

29. Ribeiro IB, Bernardo WM, Martins BDC, de Moura DTH Baba ER, Josino IR, Miyahima NT, Coronel Cordero MA, Visconti TAC, Ide E, et al: Colonic stent versus emergency surgery as treatment of malignant colonic obstruction in the palliative setting: A systematic review and meta-analysis. Endosc Int Open 6: E558-E567, 2018.

30. Ribeiro IB, de Moura DTH, Thompson CC and de Moura EGH: Acute abdominal obstruction: Colon stent or emergency surgery? An evidence-based review. World J Gastrointest Endosc 11: 193-208, 2109
31. Watt AM, Faragher IG, Griffin TT, Rieger NA and Maddern GJ: Self-expanding metallic stents for relieving malignant colorectal obstruction: A systematic review. Ann Surg 246: 24-30, 2007.

32. Pothuri B, Guirguis A, Gerdes H, Barakat RR and Chi DS: The use of colorectal stents for palliation of large-bowel obstruction due to recurrent gynecologic cancer. Gynecol Oncol 95: 513-517, 2004.

33. Carter J, Valmader S, Dalrymple C, Atkinson K and Young C: Management of large bowel obstruction in advanced ovarian cancer with intraluminal stents. Gynecol Oncol 84: 176-179, 2002.

34. Caceres A, Zhou Q, Iasonos A, Gerdes H, Chi DS and Barakat RR: Colorectal stents for palliation of large-bowel obstructions in recurrent gynecologic cancer: An updated series. Gynecol Oncol 108: 482-485, 2008.

35. Baraza W, Lee F, Brown S and Hurlstone DP: Combination endo-radiological colorectal stenting: A prospective 5-year clinical evaluation. Colorectal Dis 10: 901-906, 2008.

36. Manes G, de Bellis M, Fuccio L, Repici A, Masci E, Ardizzone S, MangiavillanoB,Carlino A, RossiGB, Occhipinti Pand Cennamo V: Endoscopic palliation in patients with incurable malignant colorectal obstruction by means of self-expanding metal stent: Analysis of results and predictors of outcomes in a large multicenter series. Arch Surg 146: 1157-1162, 2011.

37. Faraz S, Salem SB, Schattner M, Mendelsohn R, Markowitz A, Ludwig E, Zheng J, Gerdes H and Shah PM: Predictors of clinical outcome of colonic stents in patients with malignant large-bowel obstruction because of extracolonic malignancy. Gastrointest Endosc 87: 1310-1317, 2018.

This work is licensed under a Creative Commons Attribution-NonCommercial-NoDerivatives 4.0 International (CC BY-NC-ND 4.0) License. 